\title{
CARACTERIZAÇÃO MORFOMÉTRICA DE UM SISTEMA FLÚVIO-LAGUNAR NO LITORAL SEMIÁRIDO DO BRASIL (PORTO DO MANGUE - RN)
}

\author{
Iago Bezerra de Azevedo $^{(a)}$, Wanderson Silva de Araújo ${ }^{(b)}$, Ana Caroline Damasceno Souza ${ }^{(\mathrm{c})}$, \\ Diógenes Félix da Silva Costa ${ }^{(d)}$
}

(a) Grupo de Pesquisa em Geoecologia e Biogeografia de Ambientes Tropicais - TRÓPIKOS/UFRN, iago.azevedo17@gmail.com;

(b) TRÓPIKOS/UFRN, wanderson_araujo77@hotmail.com

(c) TRÓPIKOS/UFRN, anacaroline.lama@gmail.com;

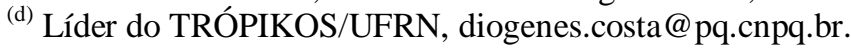

\section{Eixo: BIOGEOGRAFIA, MANEJO DE ÁREAS NATURAIS E PROTEGIDAS: CONSERVAÇÃO DA BIODIVERSIDADE}

\begin{abstract}
Resumo
Os sistemas flúvio-lagunares são ambientes comuns nas planícies costeiras mundiais, ocupam aproximadamente $12 \%$ da costa Sul-americana, maior número no Brasil. Consideram-se como laguna, corpos d'água rasos, separado do oceano por uma barreira natural. Ao longo do litoral setentrional do Rio Grande do Norte, existe uma variedade de sistemas flúvio-lagunares. Portanto, este trabalho teve como objetivo realizar a caracterização do padrão morfométrico do sistema flúvio-lagunar lagamar de Porto do Mangue (RN), a partir do uso de Sistema de Informações Geográficas e de imagens de satélite Landsat TM 5, Landsat TM 8 e Resourcesat 2 LIS3. O padrão morfométrico atibuíu-se através do índice $\mathrm{F}$ que o caracterizou como dendrítico. Constatou-se que o sistema é abastecido na dinâmica de maré alta, através do estuário do rio dos Cavalos. Apresenta ao longo de suas margens um solo hipersalino, vegetação de Savana-Estépica e mangue, com uma área inundada de acordo com a maré.
\end{abstract}

Palavras chave: Sistemas flúvio-lagunares; Laguna; Morfometria; Geoprocessamento; Porto do Mangue.

\section{Introdução}

Os sistemas flúvio-lagunares são ecossistemas comuns nas planícies mundiais, apresentando grande importância por se caracterizarem como áreas úmidas, podendo ser encontrados em regiões áridas e semiáridas (TUNDISI; MATSUMURA TUNDISI, 2008; ESTEVES, 2011). Esses sistemas são massas de água localizadas em zonas litorâneas que se encontram isoladas do mar a partir de uma barreira formada naturalmente. Ocupam cerca de $12 \%$ da costa Sul-americana, a maioria localizada no litoral brasileiro, perfazendo a costa ao longo do país.

O Rio grande do Norte possui uma variedade de lagoas costeiras ao longo do litoral setentrional. Seu caráter hipersalino pode ser claramente perceptível em alguns sistemas no norte do Estado, cujo ambiente é influenciado pelo clima tropical semiárido (COSTA; GUEDES; MOREIRA DA SILVA, 2016.).

Diante do exposto, estudos voltados a morfometria de lagoas e lagunas costeiras vêm a contribuir para um melhor entendimento acerca da influência das variações do nível do mar e consequentemente na 


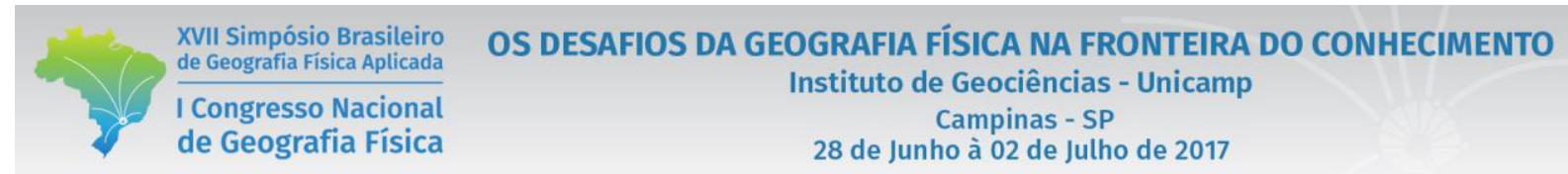

morfologia dos sistemas aquáticos. Logo, este trabalho tem como objetivo caracterizar o padrão morfométrico do maior sistema lagunar do litoral setentrional do Estado do Rio Grande do Norte (Figura 01), visando contribuir com uma avaliação das condições morfométricas que se encontram às margens da laguna, bem como analise descritiva à cerca das variações diárias do nível do mar que condicionam os processos de abastecimento da laguna. A contribuição ao conhecimento dessas variações de área inundada será realizada através de vários parâmetros analisados, dentre os quais: caracterização morfométrica do sistema; mapeamento (identificação e extensão) dos canais que abastece a laguna; e delimitação.

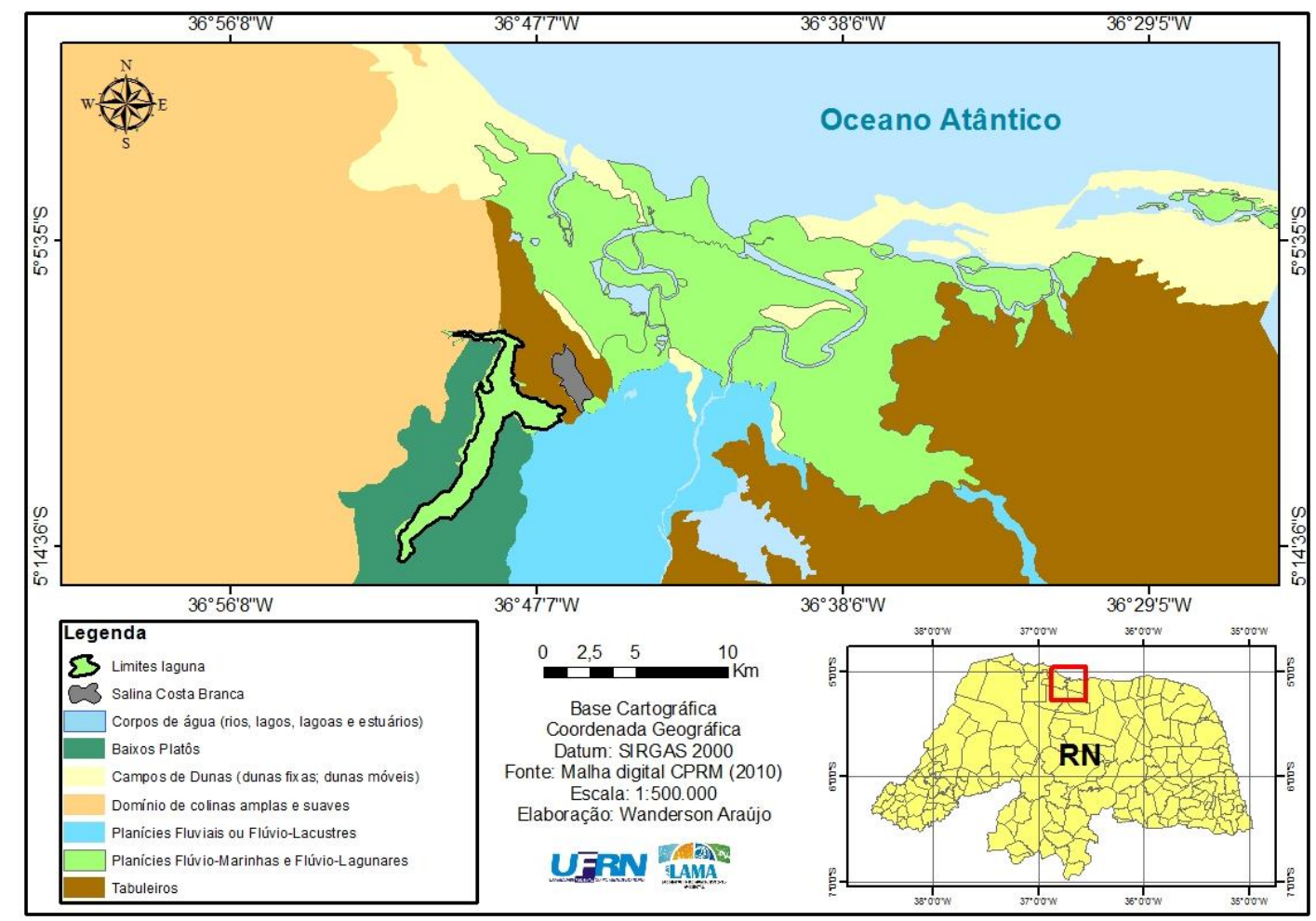

Figura 01 - Mapa geomorfológico da área de estudo

Elaboração: Araújo, W. S., (2015).

\section{Procedimentos metodológicos}

As técnicas utilizadas para elaboração dessa pesquisa seguiram as seguintes etapas: 1) levantamento bibliográfico; 2) Montagem de uma base cartográfica da área de estudo; 3) Pesquisas em campo; 4) Caracterização morfométrica do sistema.

Os materiais utilizados para estudo in locu foram: GPS (Global Positioning System), Garmin eTrex® 30 e Câmera fotográfica SONY, modelo NEX-F3. Na próxima etapa realizou-se o georreferenciamento das imagens, onde utilizou-se o software ArcGIS 10 (Versão Acadêmica). 
Para definir a morfometria da laguna lagamar, foi utilizado o Índice F, proposto por Lübbe (1977), para em seguida ser classificada segundo sua morfologia. A fórmula incide em: $F=1 / \sqrt{ } A * \pi$. Os dados do perímetro e área da laguna foram obtidos através do software ArcMap® v. 10 (Versão Acadêmica) (ESRI (C), que posteriormente obteve-se através da tabela de atributos do próprio software. O cálculo foi realizado com o auxílio do software Microsoft Excel @ (2010). A partir do valor obtido pelo Índice F, os dados foram analisados, visando classificá-la isoladamente segundo sua forma: circular/oval, alongada, composto e dendrítico. Logo, foi gerado uma tabela de atributos do ArcGis v. 10.0 com o valor do perímetro e consequentemente foi realizado o cálculo do Índice F, na qual dispôs compreender a forma que esse sistema apresenta.

\section{Resultados e discussão}

Para definir o padrão morfométrico, foram gerados dados do sistema lagamar a partir do índice F proposto por Lubble (1977), ficando constatada a heterogeneidade da lagunar lagamar, classificada como dendrítica (Figura 02).

Verificou-se que o sistema lagunar apresenta uma área equivalente a 2.687 (ha). O resultado obtido através da equação indicou que o sistema apresenta um padrão dendrítico, definição proposta por França (2008) que define a morfometria do sistema de acordo com os valores obtidos através da distribuição dos dados em forma de F, onde de acordo com o cálculo realizado o sistema obteve valor maior que 5,0 e consequentemente, classificada como dendrítica.

A laguna é preenchida na dinâmica de maré alta, através do canal de maré (gamboa) que se encontra no continente com o rio dos cavalos. O canal perfaz um curso meandrante (por consequência do baixo gradiente topográfico) e adentra cerca de $27 \mathrm{~km}$ ao continente na dinâmica de maré alta. Além dos braços do Rio Piranhas que drenam água para o sistema em épocas de cheias e dos vários tributários situados a oeste do sistema que contribuem para seu abastecimento quando ocorrem precipitações. 


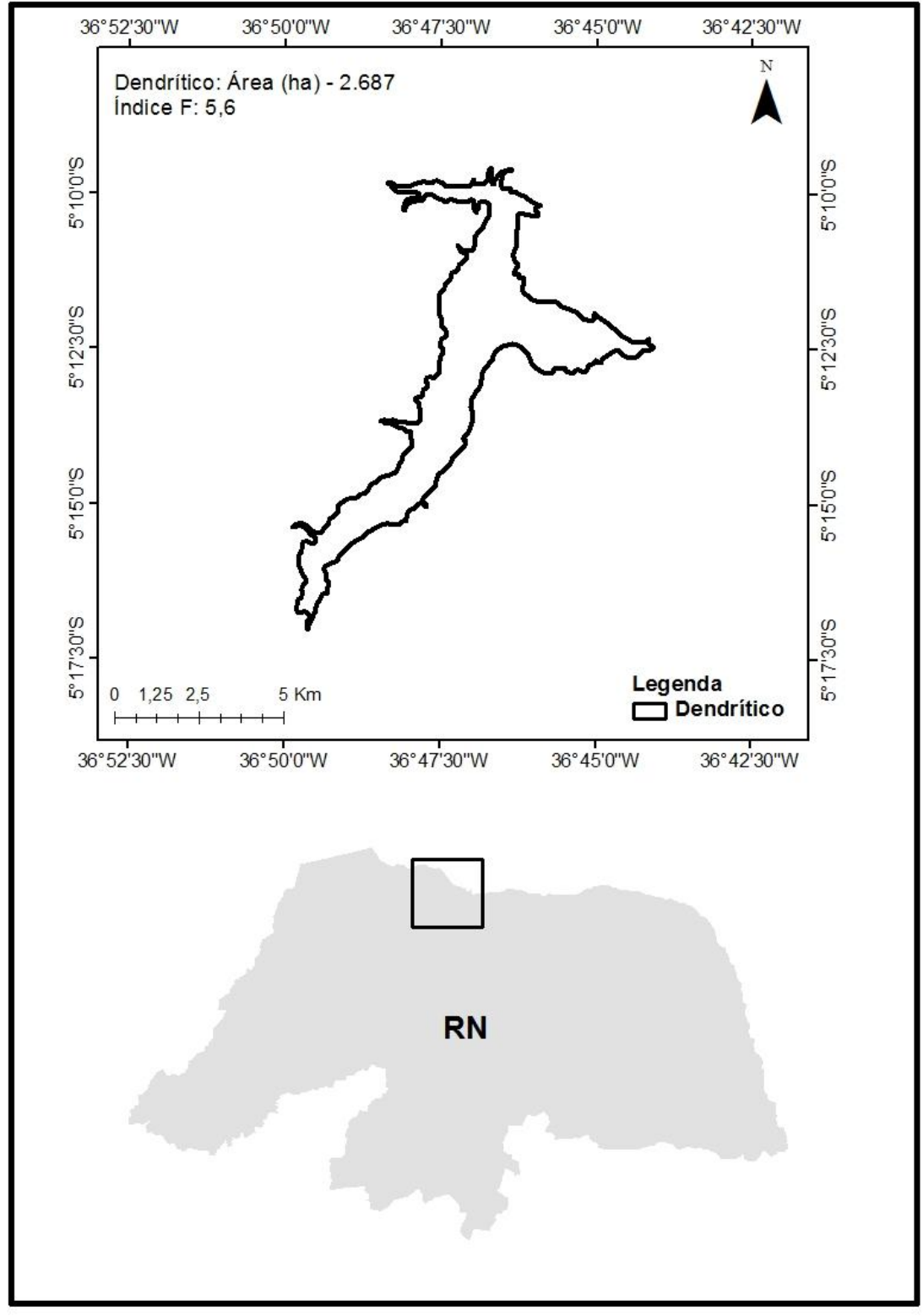

Figura 02 - Padrão morfométrico laguna lagamar.

Elaboração: Araújo, W. S., (2015).

\section{Considerações finais}

$\mathrm{O}$ índice $\mathrm{F}$ mostrou-se eficiente no cálculo morfométrico ao definir a laguna como dendrítica, apresentando uma irregularidade ao longo de suas margens. A análise morfométrica em questão vem a contribuir com uma melhor compreensão à cerca das variações hidrológicas que contribuíram para formação desses sistemas tão importantes.

A partir dos resultados expostos, conclui-se que Lagamar possui duas entradas para o mar, porém atualmente é conectada apenas pelo estuário do rio dos cavalos, sendo classificada como sufocada. Este 
apresenta $27 \mathrm{~km}$ de extensão em um curso meandrante de sua foz até a ligação com a Laguna, estando circundado em suas margens por vegetação de mangue e tanques de carcinicultura que contribuem significativamente com as condições atuais de drenagem do canal.

\section{Bibliografia}

COSTA, D. F. S.; ROCHA, R. M.; CESTARO, L. A. Análise fitoecológica e zonação de manguezal em estuário hipersalino. Mercator, v. 13, n. 1, p. 119-126, jan./abr. 2014.

COSTA, D. F. S.; GUEDES, D.R.C. ; MOREIRA DA SILVA, D. E.. Identificação dos padrões morfométricos dos sistemas lacustres e flúvio-lagunares no litoral setentrional do Rio Grande do Norte. Boletim Paulista de Geografia, v. 94, p. $65-83,2016$.

GUEDES, D. R. C. Identificação dos padrões morfométricos dos ecossistemas aquáticos costeiros no litoral setentrional do Rio Grande do Norte. 2014. Monografia (Bacharelado em Geografia) - Departamento de Geografia, Universidade Federal do Rio Grande do Norte, Caicó, 2014.

KJERFVE, B. Coastal Lagoon Processes. Elsevier Oceanography Series, Amsterdan, 1994, 577 p.

MAIA, R. P.; AMARAL, R. F.; GURGEL, S. P. P. Geomorfologia do Estado do Rio Grande do Norte. ALBANO, G. P; FERREIRA, L. S; ALVES, A. M. (Org.). Capítulos de Geografia do Rio Grande do Norte. Natal: Fundação José Augusto, 2013. p. 21- 59.

SILVA, D. E. M.; GUEDES, D. R. C.; COSTA, D. F. S. Caracterização morfométrica de sistemas flúvio-lagunares no litoral Semiárido do Brasil. Encontro Estadual de Geografia do Rio Grande do Norte, 2014, Caicó. Anais... Universidade Federal do Rio Grande do Norte, 2014.

TUNDISI, J. G.; MATSUMURA-TUNDISI, T. Limnologia. São Paulo: Oficina de textos, 2008.

ZEDLER, J. B. Wetlands at your service: reducing impacts of agriculture at the watershed scale. Frontiers in the Ecology and the Environment, v. 1, n. 2, p. 65- 72, 2003. 